\title{
Foreword
}

\section{Exploring fluid-solid interfaces with Stefan Sokołowski}

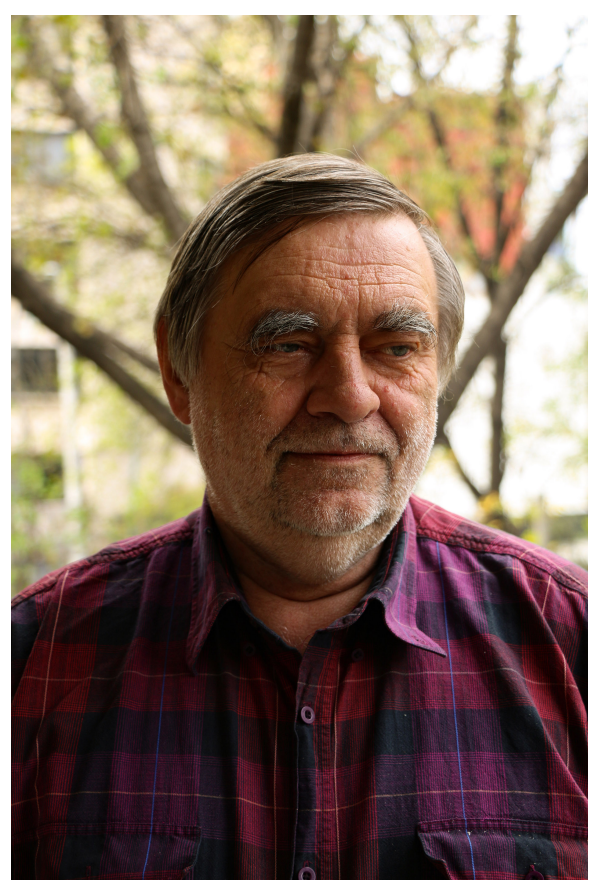

This special issue of "Condensed Matter Physics" is a collection of works prepared to mark the 65th birthday of Prof. Stefan Sokołowski, our good friend, co-worker and member of the Editorial Board of this journal. By presenting this issue we would like to add our contribution towards the celebration of his scientific achievements and valuable contributions to the science. The majority of the works in the issue deal with the description of fluid-solid interfaces by using modern statistical mechanics methods - the principal line of Stefan's research. However, some contributions from the related areas authored by his close friends are included as well.

Stefan Sokołowski was born on January 18, 1951 in a small town of Bilgoraj in eastern Poland. He began his academic training at Maria Curie-Skłodowska University (UMCS) in Lublin in 1968, receiving M.Sc. in chemistry in 1973. During his master studies, Stefan began to explore the adsorption phenomena of gases on solids in the well established scientific school of Prof. W. Rudzinski. Successful supervision of W. Rudzinski, and close collaboration with M. Jaroniec resulted in a series of original publications, see e.g., [1, 2].

Being one of the most brilliant students, he was recruited as an assistant in the Department of Theoretical Chemistry of UMCS, principally to cover laboratory and classroom teaching. However, it seems that Stefan had more ambitious plans. He already learned various theoretical and experimental methods, developed strong technical skills, and, moreover, learned how to write scientific articles on his own. Bright and profound mind combined with hunger for knowledge, with extraordinary ability to work hard in the background, pushed him to new horizons.

Thus, in 1974 he successfully passed the exams to enter the Ph.D. studies at the Institute of Physical Chemistry of Polish Academy of Science under supervision of Prof. Jan Stecki, the prominent Polish expert in statistical mechanics. After three years of hard work, in 1977, Sokołowski defended his Ph.D. thesis in chemistry, focused, however, on the topic with a stronger "flavour" of physics, namely the development and application of virial expansions to nonuniform model fluids [3-5]. Actually, the collaboration with J. Stecki inspired Stefan to undertake even more ambitious projects. The following period of his work at UMCS (1977-1983) allows him to establish himself at a new, higher rank position and implement the obtained experiences into practice. He reached several important insights in different problems ranging from pure theoretical results to several application. We have chosen to cite only a few works [6-12]. Those at least partially describe Stefan's intention to use a novel methodology like the second-order integral equations rather than the commonly used first-order ones, Monte Carlo simulations, extension of the theory to non-spherical molecules and to multicomponent fluids. The work [10] was the first, published together with A. Patrykiejew, his friend and scientific partner for many years to follow.

Taking the opportunity in search of new horizons, S. Sokołowski moved to Penn state university to become a postdoctoral fellow of W.A. Steele (1983-1984). W. Steele at that time was already very well 
known for his contributions in the theory of adsorption (summarized in the monograph [13], review in Surface Science [14] and many original contributions in the leading journals). Moreover, the lab of Steele was full of young people and was remarkable for its creative atmosphere.

Stefan used his scientific freedom with profound responsibility looking for new methods in the theory of adsorption. He involved the density functional approaches as natural extension of the previously used integral equations as well as molecular dynamics simulations to explore a wider set of problems including phase behavior of fluids under the effect of external field, see e.g., [15]-17].

Having accumulated an enormous amount of work related to the theory of adsorption and several applications made it easier for him to complete a formal last step up the academic ladder by producing habilitation thesis (1987) devoted to the comparison of a description of thermodynamics of adsorption by using two- and three-dimensional models. Having the UMCS professorship received, he still needed to await until 1997 when he was awarded the highest academic grade in Poland — the title of all-state professor in Chemistry.

In 1988 after tough selection, Sokołowski got Alexander von Humbolt Fellowship at the Institut für Thermo- und Fluiddynamic of Ruhr Universität in Bohum, where he very successfully worked with Prof. Johan Fischer. They extended several versions of density functional theory and Born-Green-Yvon integral equations to the study of mixtures in pores [18-21] and carried out molecular dynamics simulations of wetting transitions at the argon-carbon dioxide interface [22].

Many scientists at a certain period of their career attempt to change the area of research for different reasons, particularly in desire to explore something fresh or unusual compared to their previous work. Stefan made such an experiment being "seduced” by H.J. Herrmann and A.C. Gallas. To contribute into the freshly launched project on transport of the granular materials, Sokołowski moved to Forschungszentrum Jülich and worked there as a visiting professor during 1990-1991. One of the outcomes of the project was one of his highest cited works [23] on molecular dynamics simulation of granular media.

Scientific activities of many of us, including Stefan, were affected by unimaginable events in the 80s and early in the 90s, the election of the Pope of Polish nationality, the fall of Berlin wall and the crash of the communist regime in eastern Europe, preceded in Poland by martial law period, full of pain and sufferings. Stefan returned to Poland and worked at UMCS until early 1994. He arrived at Mexico City being invited by Doug Henderson to spend a year as a visiting scientist at Universidad Autonoma Metropolitana. As recalled by O. Pizio, "One evening of February that year a robust bearded guy, whom I had never seen before, entered the flat I was renting”. This was Stefan Sokołowski. Two principal projects were developed during that period. One of them dealt with the reformulation of the integral equations theory of Wertheim for bulk associating fluids to spatially inhomogeneous systems. This was a promising area that permitted to apply integral equations for the partial correlations functions, density functional approaches and computer simulations with the aim of describing the microscopic structure and thermodynamic properties of the practically important class of liquids. Henderson guided his team, with S. Sokołowski, O. Pizio and A. Trokhymchuk involved, inspired by his previous original developments [24] and principally focused on the adsorption phenomena. These activities resulted in several publications, see e.g., [25-27] for the results at the initial stage and [28] for summarizing insights. On the other hand, being geographically very far away in Ukraine, M. Holovko and his colaborators were studying a similar problem taking association as a principal point; they searched for analytical solutions, explored cooperative aspects of adsorption on peculiar solid surfaces and intended to include electrostatic interactions as well, see e.g., [29-32] for the most interesting findings.

The second project that Stefan started to work on in Mexico with Henderson et al. was an electric double layer (EDL). The principal focus there, was on the application of the density functional approach to EDL (in the version proposed previously in [33]), evaluation of the accuracy of the theory with respect to computer simulation data and searching for possible applications related to biology, see e.g., [34-38| for some important results. In search of better tools to deal with Coulomb interactions between ions in the restricted primitive model under geometric confinement and under the effect of the electric field, S. Sokołowski et al. proposed to apply the energy route to the free energy combined with a particular weighting procedure [39], in contrast to the commonly used compressibility route [33]. This appeared to be the only scheme permitting to capture the liquid-vapor phase transition in fluids of charged species that still can be improved to satisfy the contact conditions for the charge at the interface [40]. On the other hand, it appeared that for rather high temperatures, a more accurate procedure can be developed [41]. 
This modification was immediately analysed and used by Stefan. As a result, the oscillatory behavior of electric capacitance on pore width was obtained [42] in a qualitative agreement with experimental observations.

Despite numerous fellowship trips and other visits of different duration all over Europe and overseas during several years, his heart and essence of scientific existence belongs to his Alma Mater - the Maria Curie-Skłodowska University. Formally, since 1990s Stefan has been employed in the Department for the Modelling of Physicochemical Processes that was initiated as a unit of the Faculty of Chemistry of UMCS in 1996. There he teaches and realizes various scientific projects together with Małgorzata Borowko, Andrzej Patrykiejew, Wojciech Rżysko, Paweł Bryk, Katarzyna Bucior, Tomasz Staszewski. He supervised several Ph.D. students, namely G. Chmiel, J. Reszko-Zygmund, P. Bryk, K. Bucior and advised numerous colleagues from other institutions in their research. One of the recent projects of this powerful group at UMCS has been concerned with the comprehensive description of the microscopic structure, thermodynamic and electric properties, phase behavior of fluids confined to pores with walls chemically modified by brushes and pillars. To do that, extensive computer simulations and density functional approaches have been employed. Different patterns of the structural organization of modifiers at various external conditions were put in correspondence to the trends of the behavior of measurable properties [43-47]. In this manner, the group intends to optimize the computer design of nanoporous systems with desired properties and to search for novel materials with applications in chromatography. In certain aspects, similar ideas have been implemented by Sokołowski in the already developed very recent projects. In particular, Sokołowski together with Jaroslav Ilnytskyi and Taras Patsahan (Institute for Condensed Matter Physics of the National Academy of Science of Ukraine) were exploring the formation of structural patterns of mesoscopic objects within the framework of coarse-grained modelling under confinement [48 49] by using dissipative particle dynamics computer simulations. On the other hand, his interest in the elucidation of the role of orientational degrees of freedom in various properties of the homogeneous and inhomogeneous systems gave recent fruits in the density functional and computer simulation studies of the behavior of Janus fluids [50-52], and of nowadays fancy, patchy colloids [53].

One of important Stefan's scientific collaborators is his wife, Zofia Sokołowska, Professor at the Institute of Agrophysics of Polish Academy of Science, whose principal research line is physico-chemical properties of soils. For many years they have investigated the adsorption on soils, see e.g., [54-56]. However, one of the valuable contributions was in developing a new approach to analyse the mass fractal dimension of soils, this issue being of utmost importance for environmental science [57, 58].

Stefan has now published nearly 500 scientific articles, several chapters in books and reviews, see e.g., [59,-63]. His most comprehensive pedagogical contribution, written in the spirit of advanced textbook in statistical surface thermodynamics, has been just published [61]. Undoubtedly, research accomplishments by Stefan Sokołowski have been well recognized by the statistical mechanics community in physics and chemistry. As a good testimony to the quality of the results, there are currently almost five thousand citations of his contributions.

A dominating feature of Stefan is his profound desire to know more - he always wants to go to the edge of knowledge and to take advantage in applying it in theory, computer simulation and experiment. $\mathrm{He}$ is a very kind and attentive person, able to charm in science and everyday life. However, science is not the one and only passion of his. His favorite activities bringing him to a nice mood is working in the garden and cooking. His knowledge of growing and taking care of trees and flowers is extraordinary. On the other hand, kitchen is his favorite place, besides office and garden. As the acting editors of this issue, we record our pleasure of working together with Stefan in the past (several curiosities were omitted because they are out of scope of this issue), enjoy the present collaborations and look forward to realize new, common projects in the future. We wish him much health, keeping bright mind and humor and faith in future discoveries. Finally, it is our real pleasure to express our gratitude to the contributors of this special issue for their interesting articles, as well as to reviewers and technical stuff of the editorial board for their extraordinary efforts to make this project successful.

Malgorzata Borówko (Maria Curie-Skłodowska University, Lublin, Poland) Jaroslav Ilnytskyi (Institute for Condensed Matter Physics of the National Academy of Sciences of Ukraine, Lviv, Ukraine) Orest Pizio (Institute of Chemistry, National Autonomous Unversity of Mexico, Mexico City, Mexico) 


\section{References}

1. Toth J., Rudziński W., Jaroniec M., Sokołowski S., Acta Chim. Hung., 1974, 82, 11.

2. Jaroniec M., Sokołowski S., Cerofolini G.F., Surf. Sci., 1975, 47, 429; doi 10.1016/0039-6028(75)90191-0

3. Stecki J., Sokołowski S., Phys. Rev. A, 1978, 18, 2361; doi 10.1103/PhysRevA.18.2361

4. Sokołowski S., Stecki J., Mol. Phys., 1978, 35, 1483; doi 10.1080/00268977800101101

5. Sokołowski S., Stecki J., J. Phys. Chem., 1981, 85, 1741; doi 10.1021/j150612a029

6. Sokołowski S., J. Chem. Phys., 1980, 73, 3507; doi 10.1063/1.440507

7. Sokołowski S., Adv. Colloid Interface Sci., 1981, 15, 71; doi 10.1016/0001-8686(81)80003-6.

8. Sokołowski S., Mol. Phys., 1981, 44, 557; doi 10.1080/00268978100102641

9. Sokołowski S., Mol. Phys., 1983, 49, 1481; doi 10.1080/00268978300102091

10. Sokołowski S., Patrykiejew A., Mol. Phys., 1983, 50, 1311; doi $10.1080 / 00268978300103061$

11. Sokołowski S., Patrykiejew A., Thin Solid Films, 1985, 128, 171; doi 10.1016/0040-6090(85)90345-1

12. Leboda R., Sokołowski S., Rynkowski J., Paryjczak T., J. Chromatogr. A, 1977, 138, 309; doi 10.1016/S0021-9673(00)94966-5

13. Steele W.A., The Interaction of Gases with Solid Surfaces, Pergamon Press, New York, 1974.

14. Steele W.A., Surf. Sci., 1973, 36, 317; doi 10.1016/0039-6028(73)90264-1

15. Sokołowski S., Steele W.A., J. Chem. Phys., 1985, 82, 2499; doi 10.1063/1.448295

16. Sokołowski S., Steele W.A., J. Chem. Phys., 1985, 82, 3413; doi 10.1063/1.448944

17. Sokołowski S., Steele W.A., Mol. Phys., 1985, 54, 1453; doi 10.1080/00268978500101101

18. Sokołowski S., Fischer J., Mol. Phys., 1990, 71, 393; doi 10.1080/00268979000101861

19. Sokołowski S., Fischer J., J. Chem. Phys., 1990, 93, 6787; doi 10.1063/1.458948

20. Sokołowski S., Fischer J., J. Chem. Phys., 1992, 96, 5441; doi 10.1063/1.462727

21. Sokołowski S., Fischer J., J. Chem. Soc., Faraday Trans., 1993, 89, 789; doi 10.1039/FT9938900789

22. Sokołowski S., Fischer J., Phys. Rev. A, 1990, 41, 6866; doi 10.1103/PhysRevA.41.6866

23. Gallas J.A.C., Herrmann H.J., Sokołowski S., Phys. Rev. Lett., 1992, 69, 1371; doi 10.1103/PhysRevLett.69.1371

24. Henderson D., Abraham F.F., Barker J.A., Mol. Phys., 1976, 31, 1291; doi 10.1080/00268977600101021

25. Pizio O., Henderson D., Sokołowski S., J. Phys. Chem., 1995, 99, 2408; doi 10.1021/j100008a025

26. Henderson D., Sokołowski S., Pizio O., J. Chem. Phys., 1995, 102, 9048; doi 10.1063/1.468853

27. Trokhymchuk A., Pizio O., Henderson D., Sokołowski S., J. Phys. Chem., 1996, 100, 5941; doi 10.1021/jp953693s

28. Borówko M., Sokołowski S., Pizio O., In: Computational Methods in Surface and Colloid Science, Borówko M. (Ed.), Marcel Dekker, New York, 2000, Chapter 4, 167-243.

29. Holovko M.F., Vakarin E.V., Mol. Phys., 1994, 84, 1057; doi 10.1080/00268979500100741

30. Holovko M.F., Vakarin E.V., Duda Yu.Ya., Chem. Phys. Lett., 1995, 233, 420; doi 10.1016/0009-2614(94)01480-J

31. Vakarin E., Duda Y., Holovko M., J. Chem. Phys., 1997, 107, 5569; doi 10.1063/1.474233

32. Holovko M.F., Vakarin E.V., Mol. Phys., 1996, 87, 123; doi $10.1080 / 00268979650027676$.

33. Mier-y-Teran L., Suh S.H., White H.S., Davis H.T., J. Chem. Phys., 1990, 92, 5087; doi 10.1063/1.458542

34. Henderson D., Bryk P., Sokołowski S., Boda D., Rowley R., Phys. Rev. E, 2000, 61, 3896; doi $10.1103 /$ PhysRevE.61.3896

35. Boda D., Busath P.D., Henderson D., Sokołowski S., J. Phys. Chem. B, 2000, 104, 8903; doi 10.1021/jp0019658

36. Boda D., Fawcett W.R., Henderson D., Sokołowski S., J. Chem. Phys., 2002, 116, 7170; doi 10.1063/1.1464826

37. Busath D., Henderson D., Sokołowski S., J. Phys.: Condens. Matter, 2004, 16, S2193; doi $10.1088 / 0953-8984 / 16 / 22 / 019$.

38. Boda D., Henderson D., Mier-y-Teran L., Sokołowski S., J. Phys.: Condens. Matter, 2002, 14, 11945; doi $10.1088 / 0953-8984 / 14 / 46 / 305$

39. Pizio O., Patrykiejew A., Sokołowski S., J. Chem. Phys., 2004, 121 11957; doi 10.1063/1.1818677

40. Holovko M., Badiali J.P., Di Caprio D., J. Chem. Phys., 2005, 123, 234705; doi 10.1063/1.2137707

41. Wang Z., Liu L., Neretnieks I., J. Chem. Phys., 2011, 135, 244107; doi 10.1063/1.3672001

42. Pizio O., Sokołowski S., Sokołowska Z., J. Chem. Phys., 2012, 137, 234705; doi:10.1063/1.4771919

43. Borówko M., Rżysko W., Sokołowski S., Staszewski T., J. Chem. Phys., 2007, 126, 214703; doi 10.1063/1.2743399

44. Patrykiejew A., Sokołowski S., Tscheliessnig R., Fischer J., Pizio O., J. Phys. Chem. B, 2008, 112, 4552; doi $10.1021 / j p 710978 \mathrm{t}$

45. Borówko M., Rżysko W., Sokołowski S., Staszewski T., J. Phys. Chem. B, 2009, 113, 4763; doi 10.1021/jp811143n

46. Borówko M., Patrykiejew A., Sokołowski S., J. Chem. Phys., 2011, 135, 054703; doi 10.1063/1.3617413

47. Borówko M., Sokołowski S., Staszewski T., J. Phys. Chem. B, 2013, 117, 10293; doi 10.1021/jp4027546.

48. Ilnytskyi J.M., Patsahan T., Sokołowski S., J. Chem. Phys., 2011, 134, 204903; doi 10.1063/1.3592562

49. Ilnytskyi J., Sokołowski S., Patsahan T., Condens. Matter Phys., 2013, 16, 13606; doi 10.5488/CMP.16.13606

50. Borówko M., Poeschel T., Sokołowski S., Staszewski T., J. Phys. Chem B, 2013, 117, 1166; doi 10.1021/jp3105979 
51. Patrykiejew A., Sokołowski S., Sokołowska Z., Ilnytskyi Ja., J. Chem. Phys., 2013, 139, 224711; doi $10.1063 / 1.4840715$

52. Rżysko W., Sokołowski S., Staszewski T., J. Chem. Phys., 2015, 143, 064509; doi 10.1063/1.4928507

53. Sokołowski S., Kalyuzhnyi Yu., J. Phys. Chem. B, 2014, 118, 9076; doi 10.1021/jp503826p

54. Sokołowska Z., Patrykiejew A., Sokołowski S., Geoderma, 1988, 41, 327; doi/10.1016/0016-7061(88)90068-7

55. Sokołowska Z., Patrykiejew A., Sokołowski S., Langmuir, 1989, 5, 938; doi 10.1021/la00088a010

56. Kozak E., Patchepsky Ya., Sokołowski S., Sokołowska Z., Stepniewski W., Soil Sci. Soc. Am. J., 1996, 60, 1291; doi 10.2136/sssaj1996.03615995006000050002x

57. Sokołowska Z., Hajnos M., Sokołowski S., In: Fractals and Beyond: Complexities in the Science, Nowak M. (Ed.), World Scientific, London, 1998.

58. Sokołowska Z., Sokołowski S., In: Biophysical Chemistry of Fractal Structures and Processes in Environmental Systems, Vol. 11, Senesi N., Wilkinson K.J. (Eds.), Wiley \& Sons, Chichester, 2008, Chapter 6, 179-220; doi 10.1002/9780470511206.ch6

59. Henderson D., Sokołowski S., Borówko M., In: Computational Methods in Surface and Colloid Science, Borówko M. (Ed.), Marcel Dekker, New York, 2000, Chapter 3, 135-165.

60. Pizio O., Sokołowski S., In: Solid State Electrochemistry II, Kharton V.V. (Ed.), Wiley-VCH, Weinheim, 2011, Chapter 3, 73-124; doi 10.1002/9783527635566.ch3

61. Patrykiejew A., Sokołowski S., Pizio O., In: Surface and Interface Science, Vol. 6, Solid-Gas Interfaces II, Wandelt K. (Ed.), Wiley VCH, Berlin, 2016, Chapter 46, 883-1253.

62. Sokołowski S., Ilnytskyi J., Pizio O., Condens. Matter Phys., 2014, 17, 12601; doi 10.5488/CMP.17.12601.

63. Pizio O., Sokołowski S., J. Phys. Stud., 1998, 2, 296. 